\title{
Open access, open business, closed fairness!
}

\author{
Khaled Moustafai
}

\begin{abstract}
A strong trend to move from print to online publication is largely perceived in scientific and non-scientific fields, and a growing number of publishers increasingly opt for online publication as an option or a compulsory alternative. From readers' perspective, this is a highly appreciated facility, but from the author's, things are different mainly because of excessive article processing charges (APC) that make the open access system sometimes as a hindrance for many authors but a lucrative enterprise for many shareholders, enticing the most traditional and conservative publishers.
\end{abstract}

Keywords: Open access, article processing charge, golden open access, free open access.

Online publishing is gradually dominating in scientific publication industry, mainly for cost issues, rapidity of diffusion, accessibility everywhere anytime, absence of restrictive limitations related to space, and possibility to incorporate interactive illustrations that would help to better explain and understand complex scientific concepts. With the introduction of ubiquitous internet mobile devices (i.e. laptop, tablet, smartphone...etc.), online reading is also tending to predominate progressively.

Regardless of the advantages and disadvantages of open access models, the most common argumentation behind the open access policy is to spread knowledge as 'freely' and largely as possible, particularly for readers in developing countries. As a 'noble mission' as it might be, such an argumentation would not fit much because reading in those countries is almost a 'luxurious' endeavor and most people would not care about it. Rather, people in developing countries are much more concerned by how to subsist on their life than by reading scientific publications. Even if knowledge-seekers or specialists in developing countries would have chances to read such materials, they would not have means to benefit or to apply the knowledge they acquire, due to many insurmountable barriers relating chiefly to expensive costs and unavailability of work materials. The dissemination of knowledge through open-access venues is not as 'free' as presented because the openaccess fees are undeniably onerous (ranging usually from $\sim 500$ to $\$ 5000$ ), and only a reduced number of authors and institutions can afford it, particularly when many authors in same institution would publish through these venues. Moreover, many authors are often invited to edit their manuscripts by professional English editing services, which makes the real cost of the open access clearly higher than announced. Another paradoxical issue in the open-access system is that, although authors pay excessive fees, they are asked to do almost everything, beyond doing research and writing it, including for example the suggestion of 
potential reviewers (up to 8 in some cases without warrantee they will be used!). Obviously, it is a profitable business model, and unless the fees and policy of many open-access publishers would be revised toward more affordability and fairness, the notion of 'golden publishing' would be a notion of 'golden fees' much more than a notion of 'golden knowledge' disseminated 'freely'. In an ideal world, however, knowledge should be free for all, and authors should not be penalized by excessive fees for their valuable contributions to advance science and society.

On other hand, since the open access system is becoming a profitable market (a type of e-commerce), it should be subjected to the market rules in the sense that authors (clients) should be able to do "their shoppings" (their submissions) to many journals simultaneously (as a kind of 'publiquotations'). A manuscript can thus be submitted to different journals to save time, and once accepted by one of them, the submission would be withdrawn from the others. Multiple submission has the potential to reduce the delay imposed by sequential lengthy submissions and to introduce valuable competitive forces among specialized journals to eventually accelerate decisions (Torgerson, Adamson et al. 2005). Although multiple submission is already allowed in some specialties, such as law review journals (Torgerson, Adamson et al. 2005), it should be generalized to other fields to fit with the commercial dimension of the open access business, which has been transformed to a moneymaking market and should, then, be governed by the common commercial market rules. In other word, with market-oriented publication systems and excessive authors' fees, multiple simultaneous submissions would be as a 'natural' option that specialized journals should reconsider, otherwise, the open access would be an open business with closed fairness. From an editorial viewpoint, however, multiple submissions might be seen as a 'waste of time' for reviewers, but what about the author, which is the main focus of the publication process, though? Why it is tolerable that authors should accept a waste of their time to receive rejections sometime after long months of waiting, but it would not be acceptable that reviewers would waste some of time in reading manuscripts, if however we can consider reading and judging manuscript is 'waste of time'?

\section{References}

Torgerson, D. J., J. Adamson, S. Cockayne, J. Dumville and E. Petherick (2005). "Submission to multiple journals: a method of reducing time to publication?" BMJ 330(7486): 305-307.

\footnotetext{
'Email : khaled.moustafa@gmail.com
} 